\title{
THE SEX PHEROMONE OF THE BRINJAL PEST, LEUCINODES ORBONALIS GUENEE (LEPIDOPTERA) : PROBLEMS AND PERSPECTIVES
}

\section{NEELAKANTHI E. GUNAWARDENA}

Department of Chemistry, University of Kelaniya, Kelaniya, Sri Lanka.

\author{
A. B. ATTYGALLE \\ Institute of Organic Chemistry, University of Erlangen - Nurnberg, HenkestraBe 42, \\ D-8520 Erlangen, West Germany.
}

AND

H. M. W. K. BANDARA HERATH

Department of Chemistry, University of Peradeniya, Peradeniya, Sri Lanka.

(Date of receipt : 14 March 1989)

(Date of acceptance : 02 August 1989)

\begin{abstract}
Preliminary laboratory studies have shown the presence of pheromones of Leucinodes orbonalis, the brinjal shoot and pod borer found in Sri Lanka. Bioassay using an olfactometer revealed that the virgin female of $L$. orbonalis produces a sex pheromone which elicit highest response during the first night. It was also shown that the pheromone production was discontinuous, the maximum production being around $22: 00-24: 00$ hours. Chemical investigations of the pheromone gland contents of calling females showed the presence of $(E)-11$-hexadecenyl acetate as the major compound while tracer amounts of (E)-11- hexadecen-1-ol was also present. Activity of the synthetic (E)-11-HDA was shown to be equal to that of the natural sample by laboratory bio assay although in field trials the synthetic sample attracted lesser number of males.
\end{abstract}

\section{Introduction}

Leucinodes orbonalis ${ }^{10}$ Guenee, (Lepidoptera ; Pyralidae ; Pyraustinae) is recorded as the principal pest on Solanum melongena L. (Solanaceae), a popular vegetable widely grown in Sri Lanka. It is also known ${ }^{13}$ to attack other species of Solanum such as Solanum indicum, Solanum tubersum and Solanum xanthocarpum much less seriously. L. obonalis has a worldwide distribution while its presence on economic crops has been reported $9,14,16$ from many countries viz Germany, Burma, India, USA, China and Japan.

The larva of $L$. obonalis bores and feeds on the shoots and fruits of $S$. melongena, as a result of which the growth of the plant, is retarded and fruits become unsuitable for consumption. A survey conducted by Sandanayake $^{13}$ in 12 districts of Sri Lanka has shown a mean damage level of $52.5 \%$ for fruits of S. melongena by this pest. Damage levels as high as $70 \%$ of fruits have been recorded in India where it is the most destructive pest on S. melongena. Present control method is mainly the spraying of insecticides $^{8,11}$ such as Carbofuran 3G, Carbaryl, Malathion, Tamaron and Folidol. 
This method is not very effective since the above chemicals do not penetrate into the fruit where the pest spends most of its life. The use of systemic insecticides as an alternative has also been reported in the recent years. ${ }^{4 a, 17}$

Conventional insecticides used on a vast scale are meeting with increasing natural resistance which demands continuously increasing doses. Costs escalate continually as a result. Environmental pollution and destruction of beneficial species are further problems created by this practice. In recent years, much effort has been diverted to other methods of pest control such as development of resistant varieties ${ }^{1.5}$ and integrated pest management strategies. The use of pheromones ${ }^{7}$ in integrated pest management has received a great deal of attention recently. Over 670 insect pheromones have been identified since 1959, when the first pheromone Bombykol was isolated and identified. The most exploited in the pest control situations are the sex pheromones employed by insects during mating and the aggregation pheromones which bring both sexes together for feeding and reproduction. Pheromone usage has developed in three main ways viz monitoring insect population with pheromone baited traps, ${ }^{6}$ mass trapping ${ }^{6}$ where large number of traps are used to reduce pest population levels and mating disruption $^{3}$ whereby the pheromone permeates the atmosphere so as to prevent communication among the sexes and hence the subsequent mating. Although a variety of problems remain to be solved before pheromone could be used in integrated pest management as a general practice, there are considerable number of successful applications found all over the world..$^{3,6}$

Pheromone of $L$. orbanalis has not been exploited as a prospective candidate for monitoring the pest population or direct control, although chemical identification of the sex pheromone of Chinese strain of $L$. orbanalis has been reported ${ }^{12}$ quite parallel to our findings. It is apparent from these studies that the major compound in the pheromones of both strains is the same while it is difficult to conclude anything further with the limited data available. This paper presents our efforts towards developing a method to monitor the pest population of $L$. orbanalis by means of pheromones.

\section{Materials and Methods}

\subsection{Insect material}

Infected brinjals from the dry zone were spread out on a flat surface containing a layer of sawdust and were covered with paper. This was kept undisturbed for 7 to 9 days and pupae were collected. One $\mathrm{kg}$ of infected brinjals gave an average of 14 pupae which were formed preferably on sawdust. Each pupa was transferred into small polythene bags moistened with strips of filter paper. After emergence, adults were transferred to small glass vials and fed with $5 \%$ sucrose solution. 


\subsection{Preparation of Baits}

Abdominal tip extracts of virgin females were made at different time periods after emergence. First, the females were immobilised by keeping at $-20^{\circ} \mathrm{C}$ for one hour. Abdominal tips (last few segments) of females of a particular age group were excised using a micro scissor and dropped into chilled methylene chloride $(2 \mathrm{ml})$. These suspensions were kept in store at $-20^{\circ} \mathrm{C}$ or used immediately. Baits for olfactometer bioassay were prepared by homogenizing the above suspension and taking the resultant solution on to a plug of cotton wool. The solvent was allowed to evaporate before use. Blanks were prepared by the same procedure using $2 \mathrm{mls}$ of the solvent: only. Baits were prepared from the synthetic pheromone (E)-11-hexadecenyl acetate by making a stock solution ( $25 \mathrm{mg}$ in $100 \mathrm{ml}$ pentane). Required doses were pipetted out using micro pipette and applied on to the desired carriers.

\subsection{Bio assay}

\subsubsection{Laboratory bioassay}

The olfactometer described by Hershberger et al. ${ }^{5}$ was modified to suit our purpose (Figure 1). Currents of air were passed through arms A and B.by means of an air pump having an air displacement rate of.2-4 L/min. Each bait under investigation was kept in arm A while the blank was in arm B. Experiments were conducted between 20:00-22:00 hrs in a dark room with the light L as the only source of light. A tube containing batches of malès previously kept in a separate dark room was brought in and connected to tube $\mathrm{C}$ just prior to the experiment. Air circulation through the tube was commenced a few minutes after. Proceeding towards.light $\mathrm{L}$ the males encountered two air currents from which they selected the preferred arm. The number of insects in each arm and the other behavioral responses of the insects during this time were noted. Batches of five males were used at a time and each bait tested with five batches. Test insects were not used repeatedly and parts of the apparatus likely to be contaminated were also cleaned by washing and blowing air for $15 \mathrm{~min}$. 


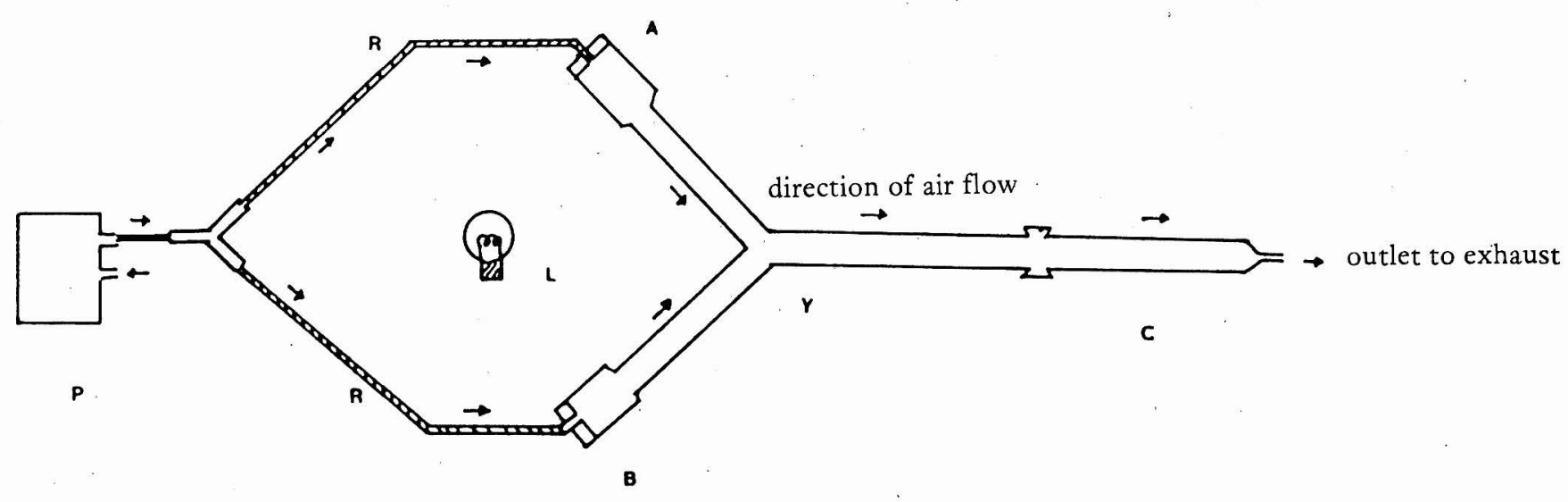

Olfactometer used in bioassay

Figure 1. Olfactometer used in the bioassay. $\mathrm{Y}-\mathrm{Y}$ shaped glass tube, $\mathrm{A}$-arm carrying the bait, B -Arm carrying the blank, $\mathrm{C}-$ Glass tube containing test insects, $\mathrm{P}-$ Air pump, L - Light, $\mathrm{R}-$ Rubber tube. 


\subsubsection{Field assay}

Field trials were carried out in the district of Kurunegala. Fields selected were reasonably infested hence had been sprayed continuously with insecticides at intervals of two weeks. For our purpose the spraying programme was ceased for one month prior to field work. Delta traps were hung at heights equal to those of brinjal plants. Traps were placed $10 \mathrm{~m}$ apart in`a randomised block design. Rubber septa dosed with lure, the blanks and three active virgin females in a small cage made out of net were placed inside the trap in the evening. Trap catch was noted and insects were sexed the following morning. Each bait was tested in three replicates and positions in the field were changed at weekly intervals.

\subsection{Identification / of the sex pheromone ${ }^{1}$}

Calling female's intersegmental membrane between segments VIII and IX was separated and encapsulated in glass capillaries before chromatographic investigations were carried out by solid sampling technique. ${ }^{2}$ Gas Liquid Chromatography-Mass Spectrometric analysis of the volatiles and comparing the MS data of peaks with those published gave the structure of the major compound. Confirmation of structures were carried out by comparing retention times on $\mathrm{SP}-2340$ fused silica capillary columns, with those of authentics.

\section{Results}

Responses evoked by abdominal tips of the virgin females excised at different times since emergence are shown in Figure 2 (a). Activity of these samples were assessed on the basis of male response measured by the mean difference $(\mu)$ of males selecting the baited arm and those selecting the nonbaited arm. Virgin females showed hardly any activity soon after emergence. Peak activity was observed during 22:00-24:00 hrs when the female was one day old. The attractiveness of the virgin female seemed to decline thereafter. Activity of synthetic (E)-11-HDA was also assessed by the similar bioassay varying only the dose (Figure $2 \mathrm{~b}$ ) and the highest activity was seen in the dose-response curve around $20 \mu \mathrm{g}$. The magnitude of this response was equivalent to that created by three virgin female equivalents.

Chromatographic investigations of two pheromone glands of $L$. orbonalis by solid sampling technique, showed a major peak (retention time $28.837 \mathrm{~min}$ ) and a minor peak (retention time $30.677 \mathrm{~min}$ ) [Figure 3]. GC -MS of the major peak showed fragmentation pattern similar to that of $\mathrm{E}-11$ - hexadecenyl acetate $\left[\mathrm{m} / \mathrm{z}, 222\left(13 \%, \mathrm{M}^{++}-60\right), 96(60 \%)\right.$, 95 (34\%), $82(70 \%), 81(53 \%), 69(36 \%), 67(55.5 \%), 68(35 \%), 61(10 \%)$, $55(100 \%), 43(84 \%)$. Retention time studies of the authentic samples confirmed that the major peak is (E)-11-HDA. Similarly minor peak was also identified as the corresponding alcohol, (E) - 11- hexadecen - 1-ol. 


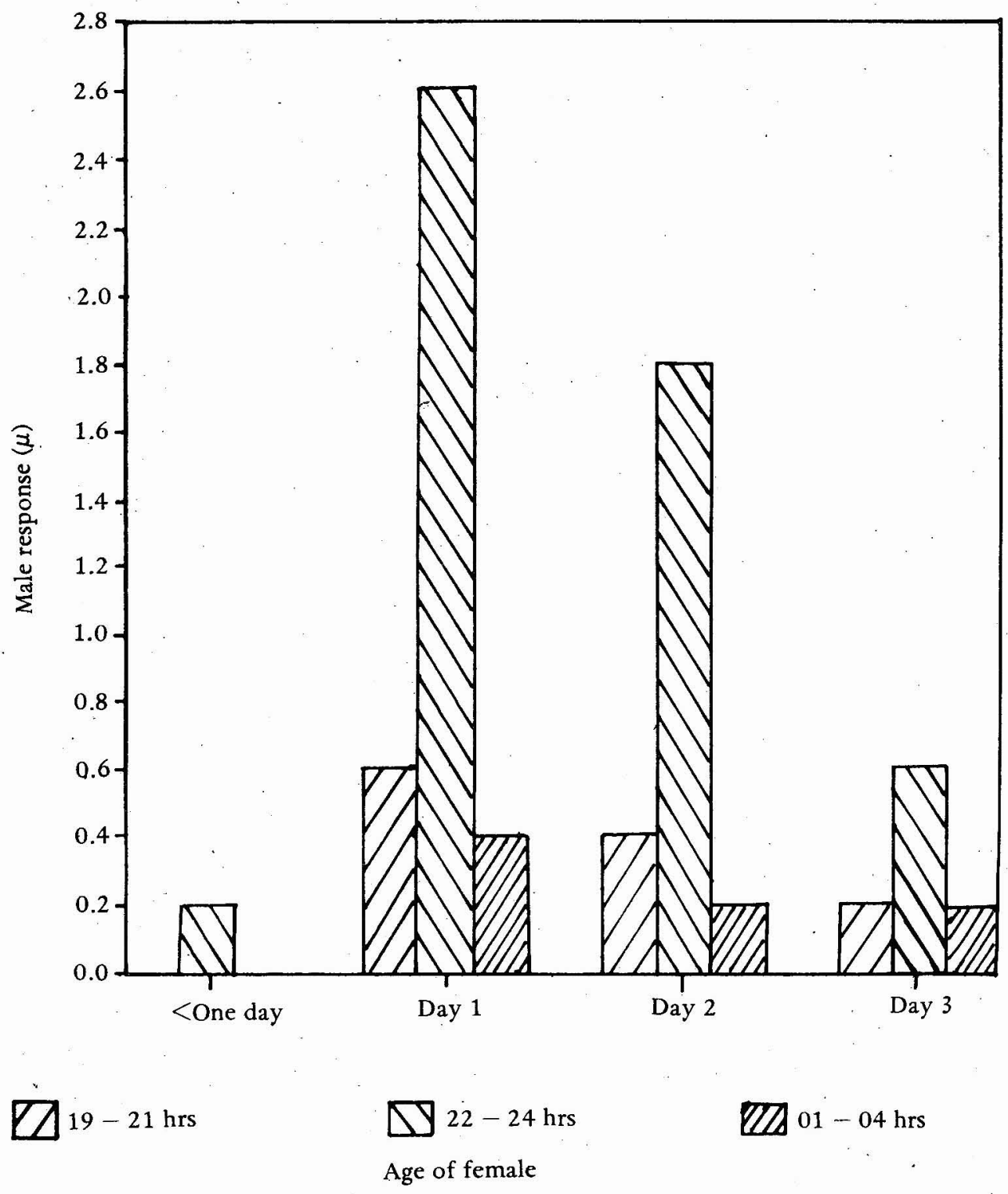

Figure 2(a). Response* profile of male Leucinodes orbanalis to age of virgin females and time.

* - Response $(\mu)=\mu_{1}-\mu_{2}$, where $\mu_{1}=$ mean number of males selecting baited arm $\mathrm{A}$ and $\mu_{2}=$ mean number of males selecting non baited arm B. 


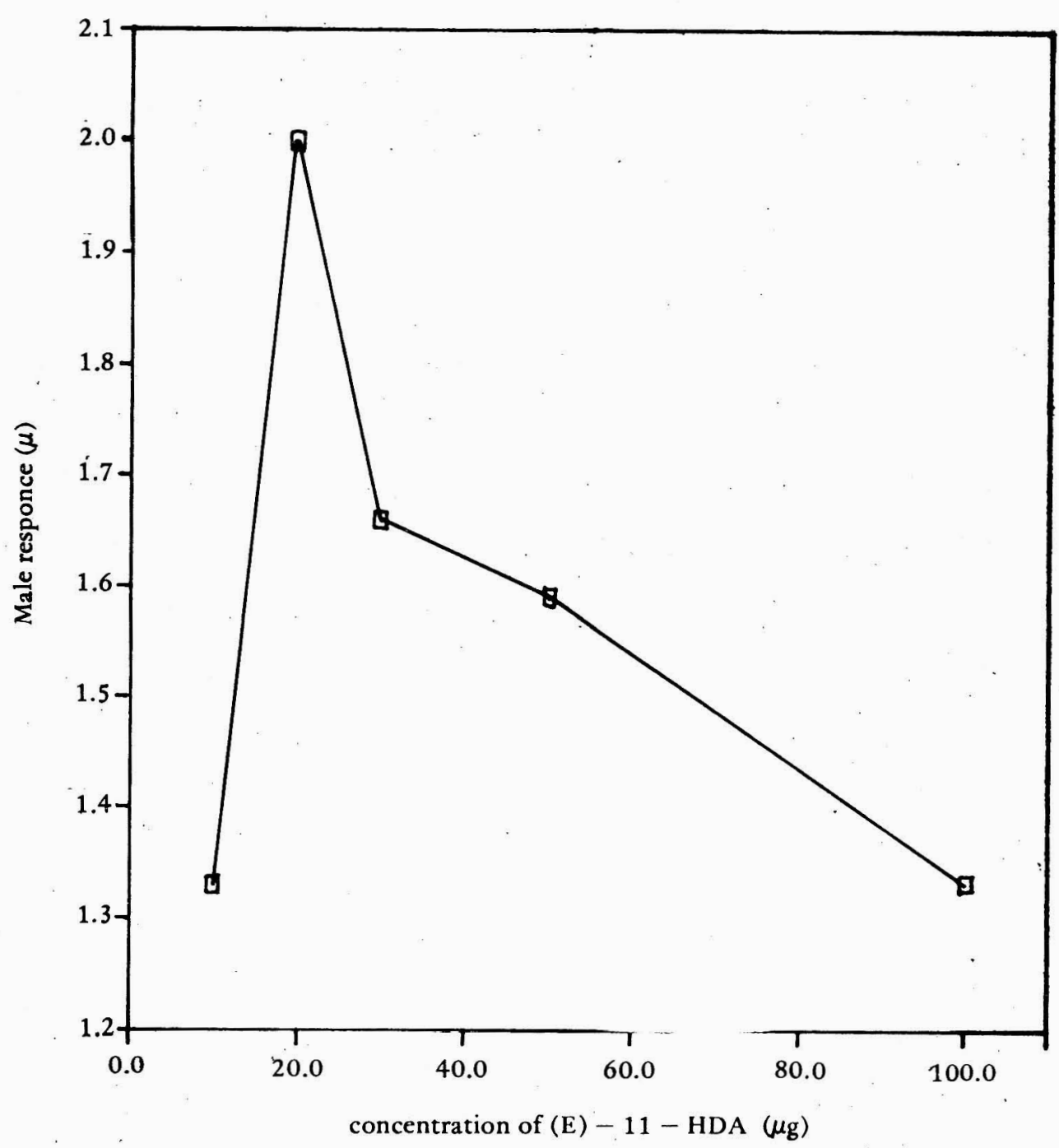

Figure 2(b). Dose - Response* Curve.

* - Response $(\mu)=\mu_{1}-\mu_{2}$, where $\mu_{1}=$ mean number of males selecting baited arm $\mathrm{A}$ and $\mu_{2}=$ mean number of males selecting non baited arm B. 


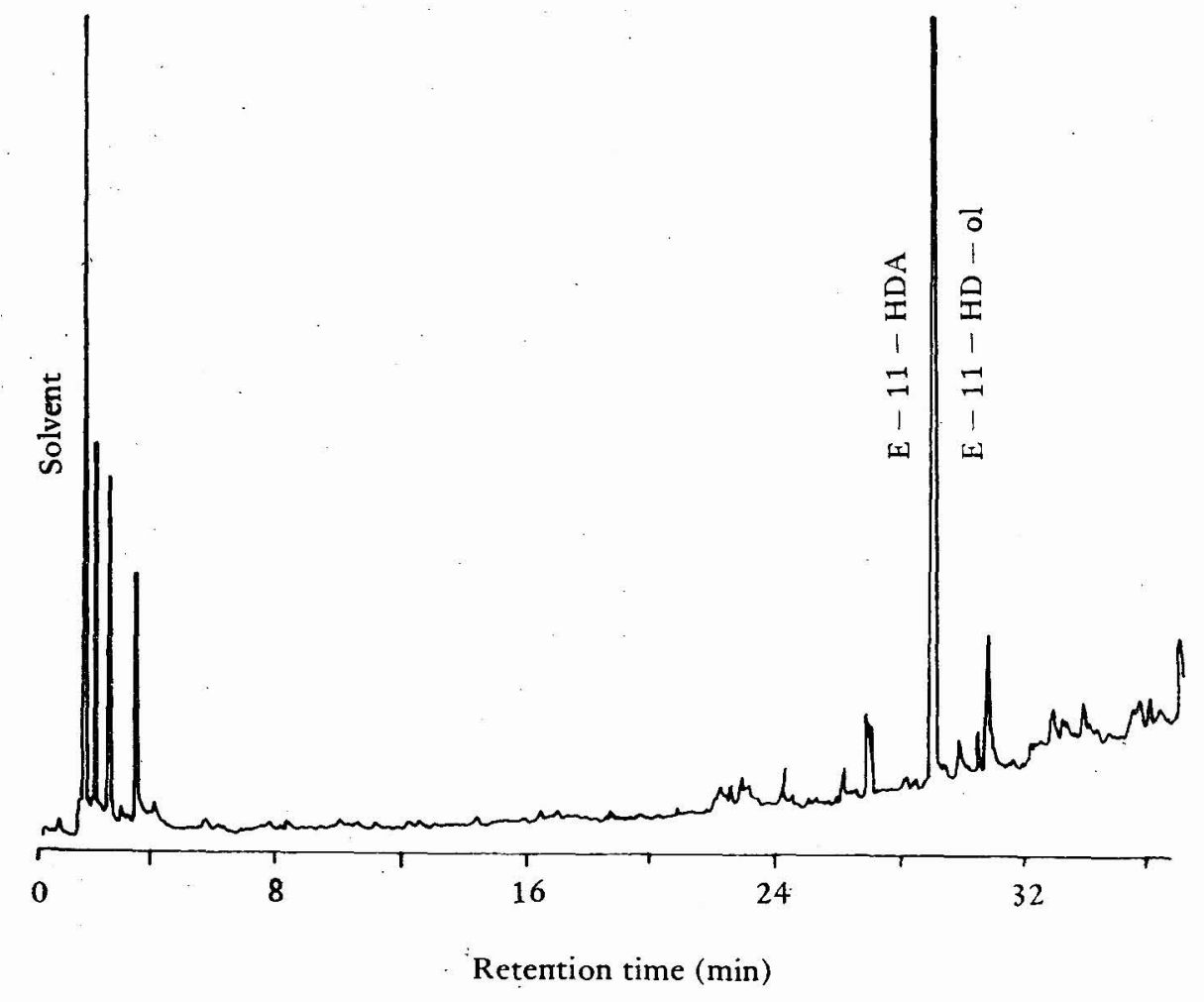

Figure 3. Gas Liquid Chromatogram of two pheromone glands of Leucinodes orbonalis.

Chromatographic conditions : Fused silica capillary column $(25 \mathrm{~m} \mathrm{X}$ $0.22 \mathrm{~mm}$ ) Stationary phase SP -2340 ; temperature programme, $60^{0} \mathrm{C}$ ( $2 \mathrm{~min}$ ) up to $195^{\circ} \mathrm{C}\left(4^{\circ} \mathrm{C} / \mathrm{min}\right)$, splitless solid sample injection.

Major and minor constituents $(E)-11$ - hexadecenyl acetate $(E-11$ $\mathrm{HDA}$ ), and $(E)-11$ - hexadecen $-1-\mathrm{ol}(\mathrm{E}-11-\mathrm{HD}-1-\mathrm{ol})$ respectively. 
The results of the field trials showed that traps containing a range of concentrations of synthetic lure attracted a lesser number of males per night per trap than those containing calling females (Table 1).

Table 1. Field attraction of Leucinodes orbanalis

\begin{tabular}{ll}
\hline Bait & Mean $^{*}$ trap catch/trap/night \\
\hline $10 \mu g-H D A$ & 00.00 \\
$200 \mu g-H D A$ & 00.00 \\
$500 \mu g-H D A$ & $00.77(0-1)$ \\
1 mg -HDA & $01.11(0-2)$ \\
3 live virgin 0 & $03.44(3-4)$ \\
blank & 00.00 \\
\hline
\end{tabular}

* - Mean of three replicates. Trials on 21st, 25th and 30th August 1988 at Boraluwewa, Kurunegala District Sri Lanka. Samples were rerandomised on last two trials.

\section{Discussion and Conclusions}

Existing control methods of $L$ orbanalis are less effective probably due to a high rate of survival of the larvae, which spent more than two thirds of its life, protected inside the brinjal fruit. The farmers quite unaware of this fact, spray insecticides at weekly intervals throughout the development of the fruit. The doses used are alarmingly high. Hazardous nature of these practices are well reflected by the fact that insecticides have been recognised as one of the causes of human deaths in Sri Lanka. ${ }^{4 b}$ An integrated pest management programme should offer a solution for the above problem. A proper monitoring programme will indicate the presence and density of pest levels in the field. This will forecast probable times of egg depositions and newly hatched larvae in the field. Spraying programmes may be commenced at this time. This will lead to a reduction of number of larvae entering into brinjal fruits. Another spraying programme could commence around three weeks after first spraying in order to destroy pupae who appear outside the fruit. Thus employing only fewer applications of insecticides, pest levels should be reduced if a proper monitoring device is available.

The attraction of synthetic pheromone, (E)-11-HDA in our field trials is somewhat encouraging though not acceptable as a potent lure. Reduced activity of this compound encountered is surprising ; however a contrast has been reported by the limited field trials done in China. ${ }^{12}$ 
Though exact trap catches have not been revealed in this report the activity of synthetic HDA has been comparable to those of calling females. This suggests that there could be a difference in the composition of pheromones between the two strains. The trace amount of $(E)-11$-hexadecene-1-ol found in the Sri Lankan sample could be the decisive factor. Further work is essential, however, before any conclusions are drawn from these findings.

In conclusion, a new formulation seems necessary to improve our trap catch. (E) -11-HDA with a tracer amount of its corresponding alcohol should be the most promising candidate. Further field trials with cheap analogues of the expensive (E)-11-HDA would also be desirable in order to make this attempt more viable.

\section{Acknowledgements}

This study was supported by the Natural Resources, Energy and Science Authority of Sri Lanka, University of Kelaniya, Institute of Fundamental Studies, Deutsche Forschungsgeminschaft and the Stiftung Volkswagenverk. Authors also thank Dr. Mrs. J. P. Edirisinghe and Mrs. M. Sandanayake of the University of the Sri Jayawardenapura for their valuable advice and help.

\section{References}

1. ATTYGALLE, A.B., SCHWARZ J. \& GUNAWARDENA N.E. (1988) $Z$. Naturforsch, 43c 790-792.

2. ATTYGALLE, A.B., HERRIG, M., VOSTROWSKY, O. \& BESTMANN, H.J. (1987) $J$. Chem. Ecol 13 (5) : 1299.

3. BROOKS, T.W., DOANE, C.C. \& HAWORTH, J.K. (1979) Proceedings, British Crop Protection Conference, Pest and Diseases, Brighton, 854-866,

4. a) HERATH, H. M. W. K. B, Personal communication.

b) HeRATH, H. M. W. K. B \& GUNAWARdENA, N.E., Personal communication, National Poisons Information Centre, General Hospital, Colombo, Sri Lanka.

5. HERSHBERGER, W.A. \& SMITH, M.P. (1967), Animal Bebav., 15, 259.

6. HUMMEL, H.E. \& MILLER, T.A. (1984), Techniques in-Pheromone Research, SpringerVerlag, New York.

7. KARLSON, P. \& LUSCHER, M. (1959), Nature, (London), 183:55-56.

8. MEHTO, D.N., SING, K.M. \& SING, R.N. (1979), Indian J.Ent. 42 (3) : 539-540.

9. MORSATT, H. (1913), Rev. App. Ent., 1:415.

10. NAYER, K.K., ANANTHAKRISHINAN, T.N: \& DAVID, B.R. (1976), General Applied Entomology, TATA McGraw Hill Publishing Company Ltd., New Delhi.

11. PUROHIT, M.L. \& KHATRI, A.K. (1973), Indian I.Agric. Sci 43(2) : 214-215. 
12. PINGCHOU, Z., FANLEI, K., SHENGDI, Y., YONGQING, SHUPING, J. XINHUA, H. \& JIANWEI, X. (1987), Z. Naturforscb. 42c : 1347-1348.

13. SANDANAYAKE, M., M.Sc Thesis (1987), Biology of the brinjal shoot and pod borer, Leucinodes orbanalis (Guen.) and its larval parasites, Tratbala flavoorbitalis (Cam.) University of Sri Jayawardanapura, Sri Lanka.

14. TAMAKI, N. \& MIYAR, A. (1982), Proceedings of the Association for plant protection of Kyushi, Japan, $28: 158-162$.

15. TEWARI, G.C. \& KRISHNAMOORTHY, P.N. (1984), Entomon, 9(1): 63-64. .

16. YANG, Z.Q. (1982) Kunchons Zbisi 19 (2) : 20-22.

17. YAZDANI, S.S., MEHTO, D.N., SING, R. \& KUMAR, A. (1981) Indian I. Ent. 43(3) : $297-301$. 